\title{
Os Movimentos eclesiais contemporâneos e Comunidades Novas: Características fundamentais
}

Renato da Silveira Borges Neto

\section{Resumo}

O artigo coloca em evidência a importância que os movimentos eclesiais contemporâneos e as comunidades novas têm assumido no âmbito da nova Eclesiologia pós-Vaticano II. Tal importância começa a ser mais e mais reconhecida diante da Igreja universal e de muitas Igrejas particulares, para além das dificuldades que possam existir na adequação dos novos carismas ao tecido eclesial destas últimas. Partindo do reconhecimento desta estima, e na busca por compreender melhor o que são estas novas realidades eclesiais, o artigo explora quatro características gerais e fundamentais presentes em todas elas. Estas características acabam por mostrar também elementos essenciais dos movimentos eclesiais contemporâneos e comunidades novas contribuindo a uma aproximação mais confiante deste fenômeno saudado por João Paulo II e Bento XVI como "resposta providencial", "sinal luminoso da beleza de Cristo e da Igreja", "hino à unidade na pluralidade desejada pelo Espírito", "colaboradores no ministério apostólico universal do Papa".

Palavras-chave: Movimentos Eclesiais Contemporâneos, Comunidades Novas, Concílio Vaticano II, Leigos. 


\begin{abstract}
The article highlights the importance of contemporary ecclesial movements and new communities have made under the new post-Vatican II ecclesiology. Such importance is beginning to be recognized more and more on the universal Church and of many particular Churches, in addition to the difficulties that may exist on the adequacy of the new ecclesial charisms of particular Churches. Recognizing this respect, and seeking a better understanding of what these new ecclesial realities, this article explores four fundamental and general characteristics present in all of them. These characteristics are also essential to show the contemporary ecclesial movements and new communities contributing to an approach more confident of this phenomenon greeted by John Paul II and Benedict XVI as "providential answer", "luminous sign of the beauty of Christ and the Church", "hymn to the unity in diversity desired by the Spirit", "collaborators in the Pope's universal apostolic ministry".
\end{abstract}

Keywords: Contemporary Ecclesial Movements, New Communities, Vatican Council II, Laity.

\title{
Introdução
}

Nos últimos anos, as intervenções magisteriais têm mostrado uma forte abertura, reconhecimento e valorização por parte da Igreja universal e de diversas Igrejas particulares em relação aos movimentos eclesiais contemporâneos e às Comunidades Novas (ou Novas Comunidades), o que tem gerado esperanças de uma maior adequação desses novos carismas ao tecido eclesial para o bem de toda a Igreja. De fato, o valor eclesiológico dessas novas comunidades e movimentos tem se tornado mais presente na consciência eclesial. Muito disto se deve, ultimamente, ao impulso dado pelos Papas Beato João Paulo II e Bento XVI. Tal abertura - aliada à progressiva consciência da missão e dignidade de filhos de Deus e da Igreja por parte dos leigos a partir do Concílio Vaticano II - tem significado uma verdadeira e própria redescoberta da dimensão pneumática desta, que nunca deixou de estar presente, mas que esteve, durante bastante tempo, um pouco obscurecida.

Deste modo, tem-se delineado um gradual alargamento da análise do tema dos novos carismas, que deixou de freqüentar somente o ambiente da 
Teologia Espiritual para participar também daquele da Teologia Dogmática. O retorno da discussão ao círculo dogmático tem sido importante para dar legitimidade à questão e para eliminar, assim, a ideia distorcida de que os movimentos eclesiais e comunidades novas representam uma realidade que diria respeito somente à vida espiritual de seus membros, mas que nada teria a ver com a Igreja enquanto tal. Pe. Jesùs Castellano mostrou muito bem a conexão que vem acontecendo em nossos dias entre o tema dos novos carismas e a Eclesiologia, quando afirmou:

De um ponto de vista teológico, a realidade das agregações e dos movimentos pertence àquele âmbito da eclesiologia que estuda, ou deveria estudar, o acontecer da Igreja a um nível carismático em formas concretas de vida, onde é possível encontrar elementos essenciais de eclesialidade que enriquecem a Igreja universal e as Igrejas particulares com a graça renovadora do Espírito. ${ }^{1}$

João Paulo II, por exemplo, aponta várias razões para o novo tempo agregativo dos leigos que estamos vivendo, especialmente depois do Concílio Vaticano II. Entre elas, ele lembra que esta nova configuração segue a "própria natureza social da pessoa e obedece à instância de uma vasta e incisiva eficácia operativa"2. Lembra também a transição epocal que a humanidade já atravessava, no contexto de um mundo secularizado e de uma sociedade pluralística e fragmentada que gera uma sensação de desnorteamento, incerteza e perplexidade.

Mas o motivo principal citado pelo Santo Padre é, porém, de natureza teológica. "Para além destes motivos [sociológicos, operacionais], a razão profunda que justifica e exige o agregar-se dos fiéis leigos é de ordem teológica: é uma razão eclesiológica, como abertamente reconhece o Concílio Vaticano II, que indica no apostolado associado um 'sinal da comunhão e da unidade da Igreja em Cristo" " 3 . Não por acaso, estes novos componentes eclesiais têm sido saudados pelos pontífices aqui evidenciados como "resposta providencial", "sinal luminoso da beleza de Cristo e da Igreja", "hino à unidade na pluralidade desejada pelo Espírito", sendo vistos como verdadeiros "colaboradores no ministério apostólico universal do Papa".

\footnotetext{
${ }^{1}$ Castellano, J. Carismi per il terzo millennio. I movimenti ecclesiali e le nuove comunità. Roma: OCD, 2001, p. 11.

${ }^{2}$ Exortação Apostólica pós-sinodal Christifideles laici, 2.

${ }^{3}$ Ibidem, 29.
} 
Trataremos neste artigo, então, das características fundamentais destas novas realidades eclesiais devido à importância e o interesse que estão despertando. Antes de tudo, porém, é importante que façamos uma premissa: usaremos indistintamente os termos "movimento eclesial" e "comunidade nova" quase como se tratassem de sinônimos. De fato, devemos nos perguntar até que ponto é concretamente possível e, até mesmo desejável, fazer hoje um aprofundamento sobre as características e diferenças específicas entre movimentos eclesiais e comunidades novas. Devemos nos perguntar se, sendo as realidades em jogo ainda bastante jovens (tratamos de realidades eclesiais contemporâneas) e navegando em um mar de vastas novidades, estamos já em condições de circunscrevê-las em claras definições, se isto é realmente conveniente ou se explicações muito estreitas neste momento não poderiam ser até mesmo perigosas e danosas. Sobre este perigo o então prefeito da Congregação para a Doutrina da Fé, o Card. Ratzinger, fez uma afirmação sobre os movimentos eclesiais que pode ser aplicada igualmente às comunidades novas: "Dever-se-ia atentar também a não se propor uma definição muito rigorosa, porque o Espírito Santo tem prontas surpresas em cada momento, e só retrospectivamente temos condições de reconhecer que por trás das grandes diversidades existe uma essência comum"4. Segundo Ratzinger, deve-se respeitar, portanto, a natureza de mobilidade e novidade própria dos movimentos eclesiais sem querer chegar apressadamente a uma definição muito precisa.

Dois outros teólogos de peso chegam mesmo a afirmar que esses os termos são sinônimos. Pe. Gianfranco Ghirlanda, já reitor da Pontificia Università Gregoriana e doutor em Direito Canônico, fundamentado em algumas intervenções de Papa João Paulo II feitas em 1998, afirma: "Baseado nestas intervenções pontifícias e outros documentos oficiais podemos considerar sinônimos os termos movimentos eclesiais, novas comunidades e novas formas de vida evangélica"s. Por sua vez, Pe. Agostino Favale nos ensina que

As realidades agregativas atuais, formadas ordinariamente por fiéis cristãos, e por isto ditas laicais, recebem nomes diversos. Normalmente fala-se de grupos, comunidades, movimentos, associações. No uso corrente, esta

\footnotetext{
${ }^{4}$ Ratzinger, J. I Movimenti ecclesiali e la loro collocazione teologica. In: Pontificium Consilium pro Laicis. I Movimenti nella Chiesa - Atti del Congresso Mondiale dei Movimenti Ecclesiali (Roma, 27-29 maggio 1998). Città del Vaticano: LEV, 1999, pp. 23-51, p. 47.

${ }^{5}$ Ghirlanda, G. Criteri di ecclesialità per il riconoscimento dei movimenti ecclesiali da parte del vescovo diocesano. In: Pontificium Consilium pro Laicis. I Movimenti Ecclesiali nella sollecitudine pastorale dei vescovi (Roma, 16 - 18 giugno 1999). Città del Vaticano: LEV, 2000, pp. 201-210, p. 201.
} 
terminologia, não carente de uma certa indeterminação e ambigüidade, é variável. Pode acontecer que os termos grupo, comunidade, movimento e associação sejam usados de maneira equivalente e intercambiável, quase como se tratasse de sinônimos. ${ }^{6}$

Assim, seguiremos estas indicações, mas com uma ressalva. Dizer que movimentos eclesiais e novas comunidades são realidades parecidas a ponto de se usar os termos como sinônimos não significa, porém, afirmar que estamos tratando, de fato, de realidades idênticas. É necessário ter cautela na avaliação de que todas essas novas realidades eclesiais sejam assim tão semelhantes, mesmo se esta é, atualmente, uma questão de importância secundária. Parece-nos simplesmente que, sendo a fase atual ainda de amadurecimento eclesial para estas novas realidades, é muito difícil traçar uma diferenciação clara e objetiva entre elas. Em nossa opinião, porém, estas realidades são colocadas no mesmo nível uma da outra muito mais pela novidade que representam. Isto não quer dizer, porém, que sejam realidades que em nada se diferenciem. De fato, mesmo sendo verdade que inicialmente as publicações dos encontros internacionais promovidos neste âmbito pelo Pontificio Conselho para os Leigos (PCL) referem-se ao termo Movimento/s, é igualmente verdade (pelo menos nos últimos anos) que a expressão novas comunidades tem, aos poucos, aparecido ao lado do termo movimentos, tanto nas publicações quanto nas falas dos pontífices, o que manifesta o acréscimo de uma nova realidade que não se reduz totalmente à outra já existente ${ }^{7}$. $\mathrm{O}$ seminário do encontro promovido pelo próprio PCL, em colaboração com a Congregação para a Doutrina da Fé e a Congregação para os Bispos, era intitulado "Os Movimentos eclesiais e Novas comunidades na solicitude pastoral dos Bispos", como para indicar duas realidades diferentes. Neste encontro, o próprio Papa João Paulo II se referia aos participantes como membros dos movimentos $e$ das novas comunidades eclesiais, separadamente ${ }^{8}$; Papa Bento XVI, por sua vez, se refere, muitas vezes, do

\footnotetext{
${ }^{6}$ Favale, A. Movimenti ecclesiali contemporanei: Dimensioni storiche, teologico-spirituali ed apostoliche. Roma: LAS, 1991, p. 14.

${ }^{7}$ Cf. Pontificium Consilium pro Laicis. La bellezza di essere cristiani. I movimenti nella Chiesa - Atti del II Congresso Mondiale dei Movimenti Ecclesiali e delle Nuove Comunità (Roma, 31 maggio - 2 giugno 2006). Città del Vaticano: LEV, 2007.

${ }^{8}$ Entre outras citações: "O que hoje é realmente um evento inédito: pela primeira vez, os movimentos e as novas comunidades eclesiais encontram-se, todos juntos, com o Papa" (Giovanni Paolo II. Agli appartenenti ai Movimenti Ecclesiali e alle Nuove Comunità nella vigilia di Pentecoste (27 maggio 1998). In: Insegnamenti di Giovanni Paolo II, vol. XXI, 1 (1998), pp. 1119-1126, n. 2, p. 1120).
} 
mesmo modo a essas realidades 9 . Isso mostra, por si só, que existe uma certa diferenciação que deverá ser, no futuro, mais claramente observada.

\section{Quatro características fundamentais dos Movimentos Eclesiais Contem- porâneos e das Comunidades Novas}

Vejamos agora quatro características genéricas e fundamentais dos movimentos eclesiais contemporâneos e comunidades novas que manifestam elementos eclesiológicos importantes.

Como, obviamente, não poderemos tratar aqui separadamente de cada movimento eclesial ou comunidade nova ${ }^{10}$, queremos simplesmente apresentar algumas características gerais, mas que pensamos relevantes, aquelas que, de alguma forma, estão presentes em todos os movimentos eclesiais e comunidades novas. Escolhemos esta metodologia exatamente por termos consciência da vastidão de características que estas novas realidades podem apresentar.

\section{1. "Movimentos... Eclesiais"}

Pode parecer óbvio, mas acreditamos ser importante destacar, antes de tudo, a natureza eclesial destas novas realidades. A Exortação Apostólica pós-sinodal Christifideles laici $\mathrm{n}$. 30 tem como título, exatamente, Critérios de eclesialidade para as agregações laicais, e procura oferecer instrumentos para que se possa verificar o quanto eclesial é uma agregação laical. Fala-se muito do caráter laical dos movimentos e comunidades novas, e esta é - sem dúvidas - uma de suas características mais importantes (trataremos dela mais a frente). É, no entanto,

\footnotetext{
${ }^{9}$ Entre outras citações: "Nos ajuda também a compreender que os movimentos eclesiais e as novas comunidades não são um problema ou um risco a mais, que se soma às nossas já gravosas incumbências. Não! São um dom do Senhor, uma reserva preciosa para enriquecer com os seus carismas toda a comunidade cristã" (Benedetto XVI. Discorso di Sua Santità Benedetto XVI ai partecipanti al Seminario per i vescovi. In: Pontificium Consilium pro Laicis. Pastori e Movimenti Ecclesiali. Seminario di studio per i vescovi (Rocca di Papa, 15 - 17 maggio 2008). Città del Vaticano: LEV, 2009, pp. 13-16, p. 15).

${ }^{10}$ Para uma lista mais completa das associações eclesiais laicais que receberam aprovação pontifícia, ver a obra: Associazioni Internazionali di Fedeli - Repertorio (LEV: 2004), organizada pelo Pontifício Conselho para os Leigos. Atualmente, é possível consultar as atualizações desse repertório através do site oficial da Santa Sé: <http://www.vatican.va/roman_curia/pontifical_ councils/laity/documents/rc_pc_laity_doc_20051114_associazioni_it.html> Esta lista - que conta hoje com 122 associações aprovadas (acesso: 08 nov. 2011) - nasceu de um pedido feito por Papa João Paulo II na Exortação Apostólica pós-sinodal Christifideles laici, 31.
} 
o seu aspecto eclesial que funda a essência destes movimentos. Existe, de fato, uma diferença crucial entre simples agregações laicais e agregações eclesiais.

As agregações eclesiais tratadas aqui são - obviamente - também laicais, mas com uma diferença marcante: se dão no interior do mistério que é a Igreja. Esse aspecto não pode ficar nas sombras. Deve-se sustentar - com Ardusso e Card. Ryłko - que esta é uma de suas características primárias e que os movimentos eclesiais não devam ser confundidos com meros movimentos laicais, mesmo se esta nomenclatura é usada, às vezes indiscriminadamente, seja por alguns teólogos, seja em alguns documentos magisteriais, devido à indeterminação terminológica que lhes é subjacente.

A identificação direta entre laical e eclesial comportaria uma redução muito perigosa e manifestaria a perda do significado específico destas novas realidades. De fato, o movimento eclesial origina-se "de uma concepção orgânica e global da natureza e da missão da Igreja, fundamentada sobre o sacerdócio comum o qual, antes de diferenciar qualitativamente o leigo do ministro ordenado, o reúne a todos os fiéis e, portanto, também aos ministros ordenados"11. O Card. Ryłko ratifica a mesma ideia quando afirma que:

Em nossos dias, uma das questões fundamentais a serem consideradas quando se fala em agregações laicais é a de sua identidade eclesial. Os termos "católico" ou "eclesial" não devem, de fato, ser reduzidos a uma função decorativa. Estes indicam a natureza mais profunda de uma agregação e supõem um programa claro de vida e de ação que deve ser compatível com esta natureza. ${ }^{12}$

Assim, enquanto o termo laical exclui o sacerdócio ministerial e o status religioso, o termo eclesial não exclui nenhum deles. Evita-se, deste modo, a oposição entre sacerdócio comum e aquele ministerial; evita-se também o isolamento e o conseqüente esquecimento da questão dos leigos, com o risco sempre latente de vê-la fora da problemática eclesial. Se tomarmos o conjunto dos documentos conciliares e os interpretarmos sob o prisma da pertença à Igreja, salta aos olhos, não o status clerical ou laical de seus membros, mas o título Povo de Deus, título que incorpora todos os Christifideles ${ }^{13}$, sejam estes

\footnotetext{
${ }^{11}$ Ardusso, F. Movimenti ecclesiali e rapporto con la Chiesa. In: I movimenti ecclesiali: esperienza e teologia. Apud: "Credere Oggi", 5 (1983), n. 17, pp. 57-69, p. 64.

${ }^{12}$ Ryłko, S. Il Concilio Vaticano II, pietra miliare nel cammino del laicato cattolico. In: Pontificium Consilium pro Laicis. Atti del Congresso del Laicato Cattolico - Testimoni di Cristo nel nuovo Millennio (Roma, 25 - 30 Novembre 2000) Città del Vaticano: LEV, pp. 115-142, p. 133.

${ }^{13}$ Expressão latina para "fiéis de Cristo". Sua origem conciliar pode ser encontrada em LG 31.
} 
fiéis leigos, fiéis sacerdotes ou fiéis religiosos e religiosas. Todos são, antes de mais nada, fiéis de Cristo! Ministérios e carismas fazem parte do universo composto pelo Povo de Deus a serviço da Igreja e do mundo. "Portanto, não existe senão um só povo de Deus escolhido por ele: "um só Senhor, uma só fé, um só batismo" (Ef 4,5); comum é a dignidade dos membros pela sua regeneração em Cristo, comum é a graça de adoção filial, comum a vocação à perfeição" ${ }^{14}$, nos afirma o Concílio. Depois, naturalmente, aparece a diversidade de formas, tarefas, ministérios e carismas. De todo modo, o qualitativo "Christifideles/Povo de Deus" permite que se supere "a bipolaridade estéril clérigos (ou hierarquia)-leigos, que desde sempre favoreceu seja a prevalência dos primeiros sobre os segundos, seja a identificação redutiva dos fiéis com os leigos"15. O Card. Pironio deixou um indicativo precioso a esse respeito, ainda na época do Sínodo sobre a missão dos leigos na Igreja e mundo (1987):

"É a hora dos leigos", ouve-se falar. Eu prefiro continuar a dizer "é a hora da Igreja". Só no interior de uma eclesiologia de comunhão integral pode-se entender "a vocação e missão dos leigos na Igreja e no mundo"; só no dinamismo de todo um povo consagrado a Deus com o sangue da nova aliança e guiado pelo Espírito Santo rumo à comunhão definitiva com o Pai, feito povo santo, sacerdotal, profético e real, pode-se falar da vocação dos leigos à santidade. ${ }^{16}$

Os movimentos e comunidades novas devem ser, antes de mais nada, eclesiais porque não podem prescindir da Igreja-mistério, sendo esta a sua referência fundamental. Também é uma de suas características essenciais acolher membros de toda a Igreja, sem distinção de estado. "São "eclesiais", porque podem pertencer a estas - e, de fato, pertencem - todas as ordens de pessoas na Igreja, leigos ou religiosos, homens e mulheres, sacerdotes e bispos, crianças e adultos, pessoas de todas as classes sociais, em espírito de comunhão entre as diversas vocações, que no Movimento "realizam a Igreja" na variedade dos seus componentes" ${ }^{17}$.

\footnotetext{
${ }^{14} L G 32$.

${ }^{15}$ Scabini, P. Vocazione e missione dei laici nei documenti conciliari e postconciliare. In: "Rivista di Vita Spirituale", 16/IV-V (1987), p. 378-389, p. 384.

${ }^{16}$ Pironio, E. La vocazione dei laici alla santità. In: "Rivista di Vita Spirituale", 16/IV-V (1987), pp. 390-406, p. 405.

${ }^{17}$ De Rosa, G. I movimenti ecclesiali oggi. In: "La Civiltà Cattolica", 155/II (2004), pp. 523-536, p. 527.
} 
Sobre esta imprescindível referência, o então Card. Ratzinger afirmou: "os movimentos nascem normalmente a partir de uma personalidade carismática guia, configuram-se em comunidades concretas que, em força de sua origem, conduzem ao Evangelho na sua inteireza e, sem hesitar, reconhecem na Igreja a razão de sua vida, sem a qual não poderiam existir"'18. Sem este vínculo constitutivo com a Igreja, portanto, os movimentos eclesiais e as comunidades novas não seriam capazes de realizar a sua missão, nem seriam reflexos dela em movimento.

Por estes motivos devemos estar atentos a não identificar imediatamente os movimentos eclesiais com os movimentos meramente laicais, o que obscureceria já de partida a tentativa de uma leitura mais eclesiológica do novo fenômeno agregativo laical na Igreja. Devemos recordar uma vez mais que esta razão agregativa é, principalmente, de natureza teológico-eclesiológica, conforme indica a Exortação Apostólica pós-sinodal Christifideles laici (cf. n. 29).

\section{A presença predominante dos leigos}

Ressalvada a importância do termo eclesiais, a segunda característica que queremos salientar é a presença predominante dos leigos nos movimentos e nas novas comunidades eclesiais. Aos participantes do Congresso Os movimentos eclesiais: comunhão e missão no limiar do terceiro milênio, o Papa João Paulo II afirmou:

O que se quer dizer, hoje, com "movimento"? [... o termo indica] uma concreta realidade eclesial com participação predominantemente laical, um itinerário de fé e de testemunho cristão que fundamenta o próprio método pedagógico sobre um carisma claro doado à pessoa do fundador em circunstâncias e formas determinadas. ${ }^{19}$

Se, por um lado, se trata de uma concreta realidade eclesial - o que é uma afirmação por si mesma muito rica de significado, como vimos anteriormente -, esta reflete também a participação predominantemente laical. Esta característica é surpreendente se considerarmos a mentalidade social que se desenvolveu nos séculos XVIII e XIX na Europa, e que se difundiu por todo

\footnotetext{
${ }^{18}$ Ratzinger, J. I Movimenti ecclesiali e la loro collocazione teologica, p. 47.

${ }^{19}$ Giovanni Paolo II. Messaggio ai partecipanti al Congresso Mondiale dei Movimenti Ecclesiali promosso dal Pontificio Consiglio per i laici (27 maggio 1998). In: Insegnamenti di Giovanni Paolo II, vol. XXI, 1 (1998), pp. 1061-1065, n. 4, p. 1064.
} 
o mundo ocidental, carregada de forte secularismo e de um estilo de vida que nada tem em comum com aquele evangélico. Através dos próprios leigos nasce uma novidade - "contra a corrente" - na Igreja. O Card. Stafford fez a seguinte leitura da relação entre a cultura ocidental fundada pelo iluminismo e o surgir de novos movimentos eclesiais: "Esta é uma cultura caduca; o Espírito Santo suscitou novos líderes leigos na Igreja com a finalidade de voltar a buscar a face de Deus, do Pai de Jesus Cristo. Me parece que a importância dos novos movimentos leigos consiste em evidenciar a sede de uma experiência cristã de fé por parte dos leigos" $" 20$. Assiste-se hoje, de fato, a uma busca sempre mais intensa de qualquer espiritualidade, mesmo se esta se revela desordenada e se traduz, muitas vezes, no aumento numérico dos membros do que se convencionou chamar de seitas $^{21}$ e das religiões ditas neopagãs ${ }^{22}$. Parece estarmos diante de um mundo que está perdendo, cada vez mais, o sentido da própria existência, em que tudo aparece fragmentado, "quebrado" - esquizofrenizado - e no qual o individualismo gera uma solidão crescente. O Prof. Guzmán Carriquiry (recentemente nomeado por Papa Bento XVI para a função de Secretário da Pontifícia Comissão para América Latina) cunhou uma bela expressão para indicar o resultado prático de tudo isso: "um mundo de solidão de massa" 23 . É justamente num mundo como este, tão desarmônico e de grandes desequilíbrios sociais, econômicos e confrontos culturais, que a religiosidade emerge novamente com força. Felizmente, no âmbito eclesial - especialmente a partir do Concílio Vaticano II -, nota-se que muitos carismas foram dados pelo Espírito Santo aos Christifideles. Mons. Eugênio Corecco, salientando o texto da $L G$ 12, afirmou que o Concílio Vaticano II, "confirmando que o carisma é dado aos 'fiéis de todas as ordens' pelo Espírito Santo e, portanto, aos clérigos, religiosos e leigos, foi extremamente libertador" 24 . No caso dos leigos não é difícil perceber como

\footnotetext{
${ }^{20}$ Stafford, J. F. I Movimenti nell'Oggi della Chiesa. In: "Nuova Umanità" XXII (2000/1) n¹27, Roma, 2000, pp. 35-49, p. 40.

21 "Na atmosfera do início do novo milênio prevalece um certo ecumenismo espiritualista, eclético, bem simbolizado pelo sincretismo de vários componentes religiosos que convergem na New Age" (Carriquiry, G. Una scommessa per l'America Latina - Memoria e destino storico di un continente. Firenze: Le Lettere, 2003, p. 244).

${ }^{22}$ São um grupo de religiões contemporâneas bastante heterogêneas entre si. A maior parte das religiões neopagãs são tentativas de reconstrução, adaptação ou ressurgimento das religiões pagãs, principalmente as da antigüidade pré-cristã européia.

${ }^{23}$ Carriquiry, G. Una scommessa per l'America Latina, p. 243.

${ }^{24}$ Corecco, E. Profili istituzionali dei Movimenti nella Chiesa. In: Camisasca, M. - Vitali, M. (Edd.). I Movimenti nella Chiesa negli anni 80 -Atti del $1^{\circ}$ Convegno Internazionale (Roma, 23 - 27 Settembre 1981). Milano: Jaca Book, 1982, pp. 203-234, p. 217.
} 
Mons. Corecco estava certo: o confirma o protagonismo assumido pelos Christifideles laici no período pós-conciliar.

Os movimentos eclesiais correspondem, assim, ao desejo de muitos cristãos de encarnar o Evangelho de Jesus Cristo de uma forma mais concreta, em um mundo cuja mentalidade (individualista, utilitarista, hedonista, tecnocentrista etc), em grande parte, os despreza. Esta mentalidade encontra hoje um freio, ou pelo menos um obstáculo, exatamente nas novas realidades eclesiais e no seu "anti-conformismo", como afirma Cattaneo: "Um dos aspectos, provavelmente, mais relevantes da missão dos movimentos é a resposta ao desafio da secularização com que se encontra confrontada a Igreja nestas últimas décadas. Compreende-se, portanto, que nos movimentos reine uma notável sensibilidade anti-conformista" 25 .

Claro está que o predomínio laical nos movimentos e comunidades novas não exclui a participação de sacerdotes, religiosos e religiosas. O nexo fundamental destas novas realidades - deve-se afirmar ainda uma vez - não está em uma separação ou divisão em status, mas exatamente na composição de uma realidade que une todos os estados de vida. A grande novidade está principalmente em seu protagonismo. Pe. Jesús Castellano nos lembra que "em outros tempos foram os leigos cristãos a acolher uma espiritualidade, na maioria dos casos, proveniente de ambiente conventual, enquanto hoje acontece exatamente o contrário: freqüentemente, de fato, nestes movimentos laicais estão envolvidos sacerdotes, religiosos e religiosas" ${ }^{26}$. De fato, "os leigos suscitam e animam movimentos nos quais os sacerdotes e os outros fiéis se encontram, se confraternizam e operam de forma concorde, movidos por um mesmo ideal que, a julgar pelos frutos, não pode ser senão um dom do Espírito"27. Hoje em dia pode-se perceber que uma grande dose de esperança e confiança é colocada sobre os leigos, o que, há algumas décadas, seria impossível sequer imaginar. Um sinal desta atitude nova pode ser visto através dos numerosos santos e santas, beatos e beatas leigos, que receberam de Papa Wojtyła o reconhecimento por suas vidas cheias de coragem heróica diante do mundo, exemplo daquele testemunho inequívoco de fé que manifesta vivamente o chamado à santidade que é destinado a todos na Igreja.

\footnotetext{
${ }^{25}$ Cattaneo, A. I Movimenti Ecclesiali: Aspetti Ecclesiologici. In: "Annales theologici” 11/II (1997), pp. 401-427, p. 407.

${ }_{26}$ Castellano, J. Tratti caratteristici dei Movimenti ecclesiali contemporanei. In: "Rivista di Vita Spirituale", 39/IV (1985), pp. 560-573, p. 562.

${ }^{27}$ Beyer, J. Il rinnovamento del diritto e del laicato nella Chiesa. Milano: Ancora, 1994, p. 140.
} 
O protagonismo dos leigos salienta e determina de maneira relevante esta mudança epocal que estamos atravessando na Igreja. Esse fato direciona a nossa atenção para elementos fundamentais da vida e da fé cristã, muitas vezes esquecidos por aqueles cristãos ditos "nominais", como a união com Cristo por meio da oração pessoal e comunitária, a verdadeira e amorosa redescoberta da Palavra de Deus e dos sacramentos (redescoberta não só intelectual, mas também afetiva), o renovado compromisso de unir cotidianamente a vida de fé e a vida prática, e o aberto testemunho cristão em todos os ambientes.

\section{Uma nova autoconsciência eclesial}

A terceira característica que gostaríamos de recordar aqui é a de uma nova autoconsciência eclesial. G. Trentin afirma que os movimentos tornam-se indubitavelmente uma "forma de promoção do laicato segundo as linhas traçadas pelo Vaticano II: é o laicato que toma consciência dos seus direitos nativos e originários derivados do batismo, incluindo o direito de criar associações" ${ }^{28}$. O protagonismo dos leigos promovido pelo Concílio Vaticano II fez com que estes desenvolvessem uma progressiva autoconsciência de sua dignidade de filhos de Deus e da Igreja. Poder-se-ia afirmar, ainda com Trentin, que "o que caracteriza os movimentos eclesiais hoje não é tanto a sua proliferação mais ou menos espontânea e inesperada, mas sim a sua consciência eclesial, a sua forma de viver e de comunicar a fé na história, sem renunciar a ser profecia, sinal de contradição, novidade"29. Esta consciência de fazer parte da Igreja - mais ainda, de ser também construtores de sua história - faz com que seus membros sintam os problemas eclesiais como próprios, envolvendo-se em primeira pessoa e empenhando-se na promoção da fé cristã de forma mais incisiva, com a própria vida. Assim, levam a Boa Notícia do Evangelho ao mundo, novidade desconcertante que experimentaram antes pessoalmente e que, exatamente por esse motivo, leva o sinal do testemunho vivo, que parece ser contagioso, por assim dizer. O confirma Mons. Domenique Rey, bispo de Fréjus-Toulon (França), que acredita também que "As novas comunidades são um potente 'fertilizante' para as vocações. Nelas, muitos batizados reencontram o sentido do seu Batismo e a dignidade da vida cristã" ${ }^{30}$.

\footnotetext{
${ }^{28}$ Trentin, G. Movimenti ecclesiali tra fede e storia. Apud: I movimenti ecclesiali: esperienza e teologia. In: "Credere Oggi", 5 (1983), n. 17, pp. 46-55, p. 46.

${ }^{29}$ Ibidem, p. 46.

${ }^{30}$ Rey, D. Accoglienza dei movimenti e delle nuove comunità nelle Chiese particolari. In: Pontificium
} 
O testemunho que nasce dessa nova autoconsciência eclesial não deixa de ser um grande desafio para estes leigos e leigas porque eles são chamados a dá-lo precisamente em meio a suas atividades cotidianas. É ali que os membros dos movimentos e comunidades novas são chamados a mostrar a consciência eclesial que vão adquirindo conforme a sua experiência de fé e encontro pessoal e comunitário com Cristo vão se aprofundando. E não poderia ser diferente. A santidade para os leigos deve ser buscada justamente em meio a suas atividades diárias no mundo. Ainda antes do ano 2000, o Card. Stafford afirmava:

O desafio que os leigos têm de enfrentar - e quando falamos destes movimentos, falamos essencialmente de leigos, enquanto nos preparamos para entrar no novo século, no novo milênio - consiste em readquirir a consciência da visão que a santidade para um leigo deve ser buscada no mundo [...], ou seja: a santidade deve ser buscada trabalhando no mundo, deve ser buscada na relação homem-mulher no matrimônio e na família, deve ser buscada na política, na economia, no mundo acadêmico, entre os jornalistas e profissionais da comunicação. ${ }^{31}$

O Concílio Vaticano II parece ter sido o grande propulsor desta nova configuração dos leigos na Igreja. "O florescimento de que foram protagonistas nas últimas décadas e os frutos da sua vigorosa ação apostólica foram propiciados, em grande parte, pela renovação eclesiológica, espiritual e pastoral promovida pelo Vaticano II" 32 , afirma Cattaneo. De fato, o decreto conciliar Apostolicam Actuosiatatem sobre o apostolado dos leigos $(A A)$ mostrou um grande horizonte aos leigos neste sentido, aguçando neles a consciência de ser Igreja e de ter dons fundamentais para a sua edificação. O decreto colocou em evidência a realidade do apostolado dos cristãos leigos exprimindo-o como direito e dever. "Os leigos derivam o dever e o direito ao apostolado da sua própria união com Cristo cabeça"33. Mais adiante, se diz: "A partir do fato de ter recebido estes carismas, mesmo os mais simples, surge para cada fiel o direito e o dever de exercê-los para o bem dos homens e a edificação da Igreja" ${ }^{34}$. Este é um esclarecimento importantíssimo do decreto, uma vez que ele evidencia o caráter destes carismas como dons especiais e direcionados ao

Consilium pro Laicis. Pastori e Movimenti Ecclesiali. Seminario di studio per $i$ vescovi (Rocca di Papa, 15 - 17 maggio 2008). Città del Vaticano: LEV, 2008, pp. 103-119, p. 112.

${ }^{31}$ Stafford, J. F. I Movimenti nell'Oggi della Chiesa, pp. 40-41.

${ }^{32}$ Cattaneo, A. I Movimenti Ecclesiali: Aspetti Ecclesiologici, p. 402.

${ }^{33} A A 3 \mathrm{a}$.

${ }^{34} A A 3 \mathrm{c}$. 
apostolado. De fato, para que possa melhor operar na vida quotidiana esse seu direito-dever, os cristãos tem necessidade de uma graça própria, uma graça especial que os faça capaz de exercitá-lo. Confirma-se, assim, a expressão dons especiais usada para determinar os carismas. De fato, "O decreto AA 3 os chama [os carismas] 'peculiaria dona' [dons especiais] num passo que depende da LG 12 para o significado de carisma" ${ }^{35}$. É a isso que se refere o Apostolicam Actuosiatatem quando diz que, "Para o exercício de tal apostolado, o Espírito Santo, que já santifica o povo de Deus por meio do ministério e dos sacramentos, distribui aos fiéis também dons particulares (1 Cor 12,7), 'distribuindo a cada um como quer' (1 Cor 12,11)" (AA 3c).

Em outras palavras - ainda com Cattaneo -, pode-se dizer que "O apostolado não é mais visto só como cooperação com a hierarquia, mas como específica missão de levar o Espírito de Cristo a todas as realidades temporais, uma missão que está aberta a inumeráveis iniciativas sejam pessoais, sejam comunitárias" ${ }^{\text {"36 }}$. É, sem dúvida, uma exortação aos fiéis leigos para que façam bom uso dos dons e carismas recebidos de Deus para o bem de toda a Igreja; independentemente de um pedido da hierarquia, é dever de todos eles enquanto cristãos. Pe. Rambaldi resume este pensamento conciliar afirmando:

Sobre o tema dos carismas, o decreto sobre o Apostolado dos leigos tem de específico, além da fórmula "direito e dever de exercê-los", também a declaração explícita que os 'peculiaria dona', ou carismas, são concedidos para o exercício do apostolado ao qual o laicato é chamado pelo batismo, pela crisma, pela participação no sacerdócio de Cristo. ${ }^{37}$

Os fiéis leigos têm, portanto, direitos e deveres em relação à sua própria fé e devem desenvolver sempre mais a sua consciência a esse respeito. A consciência eclesial dos leigos deve ser dilatada, então, no apropriar-se de cada um deles.

Mas em que consiste exatamente estes direitos e deveres? Enquanto direito, "é afirmado o indivíduo, a sua personalidade cristã, a sua responsabilidade, a sua tarefa na Igreja que, vinda do Espírito, ninguém tem o direito de impedir" ${ }^{\prime 38}$. É fundado sobre os sacramentos da iniciação cristã. M. Monnet, no seu trabalho sobre o decreto $A A$, nos faz notar como "o papel do batismo

\footnotetext{
${ }^{35}$ Rambaldi, G., Uso e Significato di 'Carisma’ nel Vaticano II. In: “Gregorianum” 56/1 (1975), pp. 141-162, p. 151.

${ }^{36}$ Cattaneo, A. I Movimenti Ecclesiali: Aspetti Ecclesiologici, p. 404.

${ }^{37}$ Rambaldi, G. Carismi e Laicato nella Chiesa. In: “Gregorianum” 68/1-2 (1987), pp. 57-101, p. 93.

${ }^{38}$ Rambaldi, G. Uso e Significato di 'Carisma' nel Vaticano II, p. 154.
} 
que insere no Corpo Místico de Cristo, da crisma que fortifica e da eucaristia que alimenta, é salientado, colocando estes sacramentos, que são partilhados por todos os cristãos, no centro da inspiração apostólica" ${ }^{39}$. De fato, como confirma Pe. Castellano: "recorre-se à raiz sacramental do batismo e da crisma, fundamento desta vocação cristã que reúne em si toda a riqueza do mistério de Cristo e do Espírito para viver o mistério eclesial" ${ }^{40}$.

Enquanto dever, por outro lado, diz-se que "A todos os cristãos [...] é imposta a nobre tarefa de trabalhar para que a mensagem divina da salvação seja conhecida e aceita por todos os homens, sobre toda a terra"41. A vocação dos fiéis leigos aparece, então, como vocação ao apostolado. Pode-se dizer que a realidade do apostolado dos cristãos é intimamente unida à sua própria fé, concebida como nobre tarefa que flui do batismo; por isto "são deputados pelo próprio Senhor ao apostolado"42. Assim,

O Espírito Santo, de quem procede o poder e o querer fazer o bem, intervém para tornar os cristãos capazes e bem dispostos em cumprir o apostolado exigido pela sua situação e pela comunidade a que pertencem, e distribui a estes os seus dons particulares, para que sejam bons dispensadores da multíplice graça de Deus para a edificação de todo o corpo na caridade. Estes dons são exatamente os carismas. ${ }^{43}$

Finalmente, os movimentos e as novas comunidades demonstram ter uma notável capacidade de despertar a consciência eclesial nos fiéis cristãos, mesmo naqueles que se afastaram há muitos anos da Igreja. Este despertar é fortemente marcado pelo seu empenho na evangelização/re-evangelização dos povos. Parece ser isto que transforma tantos homens e mulheres do nosso tempo. O Card. Danneels o notava já há mais de 25 anos: “É um fato que a maior parte das 'conversões' dos nossos dias registra-se nestes movimentos, enquanto as nossas estruturas clássicas parecem relegadas ao papel de entretenimento e de serviço" ${ }^{4}$. É também por este motivo que a paróquia parece ser

\footnotetext{
${ }^{39}$ Monnet, M-L. et al. L'Apostolato dei Laici - Decreto "Apostolicam Actuositatem". Brescia: Queriniana, 1966, p. 51.

${ }^{40}$ Castellano, J. Tratti caratteristici dei Movimenti ecclesiali contemporanei, p. 562.

${ }^{41} A A$ 3b.

${ }^{42} A A 3 \mathrm{a}$.

${ }^{43}$ Rambaldi, G. Uso e Significato di 'Carisma' nel Vaticano II, p. 152.

${ }^{44}$ Danneels, G. Evangelizzare l'Europa secolarizzata. In: "Regno-documenti” 30 (1985), pp. 578-587, p. 585 .
} 
hoje chamada a não permanecer fechada em si mesma, mas a ser "comunidade de comunidades" a fim de responder às novas demandas dos fiéis. É o que confirma o Card. Ryłko, quando afirma:

Hoje, muito freqüentemente, a paróquia é, também esta, anônima e não é capaz de constituir um espaço verdadeiramente acolhedor para os fiéis. É, então, urgente construir nas nossas paróquias uma microestrutura viva de pequenas comunidades, grupos, associações e movimentos laicais que sirvam como trâmite, criem espaços de verdadeira comunhão entre as pessoas e tornem-se verdadeiras escolas de participação ativa e de co-responsabilidade na Igreja. Estes espaços existem já em muitos lugares, mas são necessários muitos outros. ${ }^{45}$

\section{A referência à dimensão carismática da Igreja}

A quarta e última característica fundamental dos movimentos eclesiais contemporâneos que queremos salientar é expressa por aquela evidente referência à dimensão carismática da Igreja. Estamos diante de agregações que se percebem como profundamente ligadas à dimensão pneumática da Igreja. Esta dimensão parecia ter sido "esquecida" por bastante tempo. Para que existisse um novo interesse por esta realidade foi necessário um "novo evento", uma renovada manifestação daquele fenômeno carismático fundante - a efusão do Espírito Santo sobre os Apóstolos. Podemos falar de esquecimento porque o próprio Papa João Paulo II falara de redescoberta: é "desta providencial redescoberta da dimensão carismática da Igreja que, antes e depois do Concílio, afirmou-se uma linha singular de desenvolvimento dos movimentos eclesiais e das novas comunidades" ${ }^{\prime 4}$. Nos anos que se seguiram ao Concílio, de fato, percebia-se toda uma outra situação. O então Card. Ratzinger, colocando em paralelo a relação entre o termo inverno - cunhado por Karl Rahner para se referir à difícil situação pela qual passava a Igreja - e o que acontece hoje em relação aos movimentos eclesiais e comunidades novas, exprimiu-se dessa forma:

A expressão rahneriana era plenamente compreensível; exprimia uma experiência que experimentávamos todos. Mas eis que surgiu, improvisamente, algo que ninguém tinha projetado. Eis que o Espírito Santo, por assim dizer, tinha pedido outra vez a palavra. E em jovens, homens e mulheres, reflorescia a fé, sem "se" nem "mas", sem subterfúgios

\footnotetext{
${ }^{45}$ Ryłko, S. Il Concilio Vaticano II, pietra miliare nel cammino del laicato cattolico, pp. 135-136.

${ }^{46}$ Giovanni Paolo II. Agli appartenenti ai Movimenti Ecclesiali e alle Nuove Comunità, n. 4, p. 1122.
} 
nem brechas, vivida na sua integralidade como dom, como um presente precioso que faz viver. É claro, não faltou quem visse isso como algo que incomodaria seus debates intelectualistas e projetos de construção de uma Igreja diferente e feita à sua própria imagem. E como poderia ser diferente? Onde irrompe, o Espírito Santo desfaz sempre os projetos dos homens. ${ }^{47}$

O Prof. Guzmán Carriquiry comenta nestes termos aquele confuso período da Igreja: "Não resta dúvida que se tratou de um inverno rigoroso para a Igreja. Se aprende e se cresce somente quando se enfrenta toda a realidade sem censurar nenhuma parte nem dimensão constitutiva. No auge da crise do pós-concílio, no dia 7 de dezembro de 1968, Paulo VI dizia: 'A Igreja encontra-se em uma hora de inquietação, de autocrítica, se diria até mesmo de autodestruição' e punha, então, toda a confiança em Cristo: "será Ele que acalmará a tempestade""48. Parece mesmo que as palavras do Pontífice tornaram-se realidade, pelo menos em parte, com a redescoberta daquela dimensão essencialmente carismática da Igreja. Hoje, pode-se perceber uma situação diferente daqueles anos pós-conciliares ${ }^{49}$, uma situação que há poucas décadas atrás pareceria impensável diante de uma Igreja que se encontrava confusa e sem vigor. Referindo-se a esse momento histórico, Pe. Albert Vanhoye observava:

Em nossos tempos, a situação mudou e a mudança provoca estupor e interrogações. Em toda parte formaram-se diversos grupos cristãos nos quais se reproduzem, pelo que parece, experiências da Igreja primitiva, fenômenos de glossolalia, "batismo no Espírito", curas por imposição das mãos etc. Por estes motivos, os textos do Novo Testamento sobre os carismas tomaram uma atualidade nova, que se repercute até sobre outros aspectos da vida da Igreja. ${ }^{50}$

De tempos em tempos, a estória se repete: alguém (ou um grupo de pessoas) faz uma experiência carismática na Igreja, decisiva para a própria vida, e que depois, de maneira misteriosa, estende-se a outros. A partir deste

${ }^{47}$ Ratzinger, J. I Movimenti ecclesiali e la loro collocazione teologica, p. 24.

${ }^{48}$ Carriquiry, G. Una scommessa per l'America Latina, p. 230.

${ }^{49}$ Não queremos, com esse paralelo, subestimar os atuais desafios da Igreja que são enormes. Esta continua o seu árduo caminho em meio às grandíssimas dificuldades do início do novo milênio. Estamos somente destacando o contrastante estado de confiança e entusiasmo que surgiu depois do "inverno" de Karl Rahner, chamado por João Paulo II de "primavera".

${ }^{50}$ Vanhoye, A. I Carismi nel Nuovo Testamento (ad uso degli studenti). Roma: Pontificio Istituto Biblico, 2002, p. 4. 
primeiro encontro nasce um caminho de santidade e aprofundamento na fé para si e para tantas outras pessoas que depois venham a ter contato e desejem acolher aquele carisma na própria vida. "O fator fundamental, presente na raiz de tudo, está ligado, portanto, a um acontecimento, isto é, a algo que aconteceu, que fez, às vezes discretamente, irrupção na vida dos homens, levando-a por caminhos não aplainados e colocando-a em movimento" ${ }^{51}$, afirma o Prof. Fidel González. Este fator fundamental é substancialmente pneumatológico, reflexo da carismaticidade da própria Igreja. Moysés Azevedo, Fundador da Comunidade Católica Shalom, recordou durante o II Seminário de estudo para os Bispos, intitulado "Pastores e movimentos eclesiais":

A força deles [dos movimentos e novas comunidades] está no carisma recebido por Deus para propor aos homens do nosso tempo, com a Igreja e na Igreja, a experiência concreta de Jesus Cristo vivo. Dessa experiência nasce a alegria de ser cristãos, a necessidade de pertencer à Igreja e de viver a vida sacramental; esta experiência gera comunidades cristãs maduras, com laços de amor e fraternidade, conduz a descobrir a força da Palavra de Deus e da oração, o amor e o serviço aos pobres, materiais ou morais; esta experiência nos empurra a evangelizar. ${ }^{52}$

Os movimentos eclesiais contemporâneos e as novas comunidades fazem, portanto, referência a um evento único e fundamental que remete à índole carismática da Igreja: uma nova intervenção do Espírito Santo que tende a se amplificar rapidamente. Estimava-se, ainda no ano 2000, que só o movimento da Renovação Carismática Católica (RCC) estivesse "difundido em 204 países dos cinco continentes entre 82 milhões de católicos"53. Hoje sabe-se que são mais de 100 milhões. O Movimento dei Focolari fundado na Itália, em 1943 - e que em 14 de março de 2008 perdeu a sua fundadora, Chiara Lubich -, por sua vez, está presente em 182 países e possui mais de 180 mil membros e 2 milhões de aderentes e simpatizantes. A Comunidade Católica Shalom

${ }^{51}$ González, F. Carismi e movimenti nella storia della Chiesa. In: Pontificium Consilium pro Laicis. I Movimenti Ecclesiali nella sollecitudine pastorale dei vescovi (Roma, 16 - 18 giugno 1999). Città del Vaticano: LEV, 2000, pp. 71-103, p. 72.

${ }^{52}$ De Azevedo, Moysés L. Umili servi nella vigna del Signore. In: Pontificium Consilium pro Laicis. Pastori e Movimenti Ecclesiali. Seminario di studio per i vescovi (Rocca di Papa, 15 - 17 maggio 2008). Città del Vaticano: LEV, 2009, pp. 203-209, p. 205.

${ }^{53}$ Martinez, S. Rinnovamento nello Spirito Santo. In: Pontificium Consilium pro Laicis. I Movimenti Ecclesiali nella sollecitudine pastorale dei vescovi (Roma, 16 - 18 giugno 1999). Città del Vaticano: LEV, 2000, pp. 171-181, p. 171. 
(Moysés Louro de Azevedo Filho, 1982) e a Comunidade Canção Nova (Pe. Jonas Abib, 1978) - comunidades novas fundadas no Brasil - estão presentes em oito e cinco países, respectivamente; só para citar um exemplo, a primeira conta hoje com cerca de 4.000 membros e 40.000 aderentes. Estes são somente alguns exemplos - ainda poderíamos citar muitas outras comunidades novas, inclusive brasileiras - que nos permitem afirmar que vivemos um momento eclesiológico especial, ou seja, um tempo de reflorescimento que parece rejuvenescer a face da Igreja (inclusive pela atratividade que exercem sobre os jovens, cada vez mais distantes), facilitando o diálogo com muitos fiéis, distanciados - talvez - pela frieza de um modelo de Igreja que já aparecia carente de entusiasmo ou demasiadamente apegado somente a cânones, ritos e leis ${ }^{54}$. O colocar em evidência a dimensão carismática da Igreja se alinha muito bem à nova eclesiologia proposta pelo Concílio Vaticano II, que tem como fruto a elaboração de "uma nova imagem do mistério da Igreja que se liga às origens do cristianismo, uma visão da Igreja como organismo vivo, que é vivificado e unificado pelo Espírito Santo"55.

Assim, poderíamos identificar os efeitos da ação criadora do Espírito Santo na Igreja do nosso tempo também no surgimento desses movimentos eclesiais e comunidades novas; eles são frutos da índole carismática da própria Igreja. Mons. Alberto Taveira, Arcebispo Metropolitano de Belém $\mathrm{PA}$, recorda que

No curso da história da Igreja, o Senhor nunca deixou de repetir a sua Palavra, anunciando-a de vez em quando com "palavras" novas. Por meio de diversos carismas, Deus continua ainda hoje a dirigir-nos as suas palavras através de testemunhos concretos na vida da Igreja. Todos os carismas, grandes e pequenos, são chamados a levar a Palavra aos homens

\footnotetext{
${ }^{54}$ Devemos lembrar, porém, que o período de reflorescimento e redescoberta vivido atualmente é inseparável do período de crise pré e pós-conciliar. De fato, não se deve perder de vista a associação íntima entre estes dois momentos; caso contrário, arrisca-se a não compreender-se adequadamente o movimento do Espírito Santo na História. A este propósito, o Prof. Carriquiry recorda que "Aqueles que viram só o inverno, ficaram na impotente nostalgia de uma crítica exasperada que acusa injustamente o próprio Concílio e os seus ensinamentos. Aqueles que somente cantam os louvores da primavera, exorcizam a cruz concreta e pesada que foi levada com sofrimento, e que é prova e julgamento para a conversão e para a ressurreição" (Carriquiry, G. Una scommessa per l’America Latina, pp. 231-232).

${ }_{55}$ Blanchnicki, F. Aspetti caratterizzanti un movimento ecclesiale. In: Camisasca, M. - Vitali, M. (Edd.). I Movimenti nella Chiesa negli anni 80 -Atti del $1^{\circ}$ Convegno Internazionale (Roma, 23 - 27 Settembre 1981). Milano: Jaca Book, 1982, pp. 175-202, p. 179.
} 
do nosso tempo, sobretudo a palavra da caridade. De fato, são dados a uma pessoa ou a um grupo de pessoas "para" os outros e "para" a Igreja, não certamente para aumentar a própria vanglória. ${ }^{56}$

A esse respeito, foram vigorosas as palavras proferidas pelo Papa João Paulo II diante da multidão dos membros dos movimentos e comunidades novas, quando exprimiu a sua própria admiração pelo que realiza o Espírito Santo no hoje da Igreja: "Hoje a Igreja se alegra em constatar renovadamente o tornar-se verdade das palavras do profeta Joel: 'Eu efundirei o meu Espírito sobre toda pessoa' (At 2,17). Vocês aqui presentes são a prova tangível desta 'efusão' do Espírito" ${ }^{57}$.

\section{Conclusão}

A inserção dos movimentos eclesiais contemporâneos e das comunidades novas no seio das Igrejas particulares continua a ser hoje um dos maiores desafios tanto para os muitos Bispos, quanto para estas próprias novas realidades eclesiais. Conhecer suas características fundamentais passa a ser, assim, um caminho indispensável para delas se aproximar com mais confiança.

Como pudemos perceber, os movimentos eclesiais contemporâneos e as comunidades novas contribuem hoje para a renovação da Igreja juntamente com tantas outras expressões eclesiais. Os carismas destas novas realidades eclesiais são apontados como uma obra do Espírito, um dom de Cristo-Esposo à Igreja-Esposa que deve ser acolhido com gratidão e esperança, como confirmam os pronunciamentos dos últimos Sumos Pontífices. As quatro características vistas aqui foram escolhidas em meio a muitas outras por serem capazes de mostrar o que parece ser uma realidade comum nessas novas expressões da Igreja e, assim, indicar elementos importantes a serem considerados.

As palavras de Papa Bento XVI aos participantes do II Seminário de estudo dos bispos (que recuperavam, na ocasião, a sua exortação aos bispos da Conferência Episcopal Alemã presentes a Roma durante uma visita ad limina: "Vos peço para ir ao encontro dos movimentos com muito amor") são bastante reveladoras. Pareciam querer contribuir, decididamente, para que se

\footnotetext{
${ }^{56}$ Taveira, Alberto. Discerimento dei carismi: alcuni criteri pratici. In: Pontificium Consilium pro Laicis. Pastori e Movimenti Ecclesiali. Seminario di studio per i vescovi (Rocca di Papa, 15 - 17 maggio 2008). Città del Vaticano: LEV, 2009, pp. 97-102, p. 97.

${ }^{57}$ Giovanni Paolo II. Agli appartenenti ai Movimenti Ecclesiali e alle Nuove Comunità nella Vigilia di Pentecoste, n. 5, p. 1122.
} 
dirimisse qualquer dúvida sobre a importância e a oportunidade de as Igrejas particulares acolherem as novas realidades eclesiais como um dom do Espírito Santo. Suas palavras indicavam a necessidade de as Igrejas locais conhecerem melhor esses novos carismas e de se abrirem a eles com confiança:

Ir ao encontro dos movimentos e comunidades novas com muito amor nos impulsiona a conhecer adequadamente a realidade deles, sem impressões superficiais ou juízos redutivos. Nos ajuda também a compreender que os movimentos eclesiais e as novas comunidades não são um problema ou um risco a mais, que se soma às nossas já gravosas incumbências. Não! São um dom do Senhor, uma reserva preciosa para enriquecer com os seus carismas toda a comunidade cristã. Por isso não deve faltar um acolhimento confiante que lhes dê espaços e valorize a sua contribuição na vida das Igrejas locais. Dificuldades ou incompreensões não autorizam ao fechamento. $\mathrm{O}$ "muito amor" inspire prudência e paciência. ${ }^{58}$

Bento XVI parece mesmo seguir os passos de seu predecessor, Papa João Paulo II, que via nesses movimentos e comunidades novas uma oportunidade única para a Igreja:

Que necessidade tem-se hoje de personalidades cristãs maduras, conscientes da própria identidade batismal, da própria vocação e missão na Igreja e no mundo! Que necessidade de comunidades cristãs vivas! E eis, então, os movimentos e as novas comunidades eclesiais: eles são a resposta, suscitada pelo Espírito Santo, a este dramático desafio de fim de milênio. Vocês são esta resposta providencial..$^{59}$

\section{Referências Bibliográficas}

ARDUSSO, F. Movimenti ecclesiali e rapporto con la Chiesa. In: Imovimenti ecclesiali: esperienza e teologia. Apud: "Credere Oggi”, 5 (1983), n. 17, pp. 57-69.

BENEDETTO XVI. Discorso di Sua Santità Benedetto XVI ai partecipanti al Seminario per i vescovi. In: Pontificium Consilium pro Laicis. Pastori e Movimenti Ecclesiali. Seminario di studio per $i$ vescovi (Rocca di Papa, 15 - 17 maggio 2008). Città del Vaticano: LEV, 2009, pp. 13-16.

\footnotetext{
${ }^{58}$ Benedetto XVI. Discorso di Sua Santità Benedetto XVI ai partecipanti al Seminario per i vescovi, p. 15. ${ }^{59}$ Giovanni Paolo II. Agli appartenenti ai Movimenti Ecclesiali e alle Nuove Comunità nella vigilia di Pentecoste, n. 7, p. 1123.
} 
BEYER, J. Il rinnovamento del diritto e del laicato nella Chiesa. Milano: Ancora, 1994.

BLANCHNICKI, F. Aspetti caratterizzanti un movimento ecclesiale. In: Camisasca, M. - Vitali, M. (Edd.). I Movimenti nella Chiesa negli anni 80 -Atti del $1^{\circ}$ Convegno Internazionale (Roma, 23 - 27 Settembre 1981). Milano: Jaca Book, 1982, pp. 175-202.

CARRIQUIRY, G. Una scommessa per l'America Latina. Memoria e destino storico di un continente. Firenze: Le Lettere, 2003.

CASTELLANO,J.Tratticaratteristicidei Movimentiecclesialicontemporanei. In: "Rivista di Vita Spirituale", 39/IV (1985), pp. 560-573.

. Carismi per il terzo millennio. I movimenti ecclesiali e le nuove comunità. Roma: OCD, 2001.

CATTANEO, A. I Movimenti Ecclesiali: Aspetti Ecclesiologici. In: "Annales theologici" 11/II (1997), pp. 401-427.

CORECCO, E. Profili istituzionali dei Movimenti nella Chiesa. In: Camisasca, M. - Vitali, M. (Edd.). I Movimenti nella Chiesa negli anni 80 -Atti del $1^{\circ}$ Convegno Internazionale (Roma, 23 - 27 Settembre 1981). Milano: Jaca Book, 1982, pp. 203-234.

DANNEELS, G. Evangelizzare l'Europa secolarizzata. In: "Regnodocumenti" 30 (1985), pp. 578-587.

DE AZEVEDO, Moysés L. Umili servi nella vigna del Signore. In: Pontificium Consilium pro Laicis. Pastori e Movimenti Ecclesiali. Seminario di studio per $i$ vescovi (Rocca di Papa, 15 - 17 maggio 2008). Città del Vaticano: LEV, 2009, pp. 203-209.

DE ROSA, G. I movimenti ecclesiali oggi. In: "La Civiltà Cattolica", 155/II (2004), pp. 523-536.

FAVALE, A. Movimenti ecclesiali contemporanei: Dimensioni storiche, teologico-spirituali ed apostoliche. Roma: LAS, 1991.

GIOVANNI PAOLO II. Messaggio ai partecipanti al Congresso Mondiale dei Movimenti Ecclesiali promosso dal Pontificio Consiglio per i laici $(27$ maggio 1998). In: IGP-II, vol. XXI, 1 (1998), pp. 1061-1065; 
- Agli appartenenti ai Movimenti Ecclesiali e alle Nuove Comunità nella vigilia di Pentecoste $(27$ maggio 1998). In: Insegnamenti di Giovanni Paolo II, vol. XXI, 1 (1998), pp. 1119-1126;

GHIRLANDA, G. Criteri di ecclesialità per il riconoscimento dei movimenti ecclesiali da parte del vescovo diocesano. In: Pontificium Consilium pro Laicis. I Movimenti Ecclesiali nella sollecitudine pastorale dei vescovi (Roma, 16 - 18 giugno 1999). Città del Vaticano: LEV, 2000, pp. 201-210.

GONZÁLEZ, F. Carismi e movimenti nella storia della Chiesa. In: Pontificium Consilium pro Laicis. I Movimenti Ecclesiali nella sollecitudine pastorale dei vescovi (Roma, 16 - 18 giugno 1999). Città del Vaticano: LEV, 2000, pp. 71-103.

MARTINEZ, S. Rinnovamento nello Spirito Santo. In: Pontificium Consilium pro Laicis. I Movimenti Ecclesiali nella sollecitudine pastorale dei vescovi (Roma, 16 - 18 giugno 1999). Città del Vaticano: LEV, 2000, pp. 171-181.

MONNET, M-L. et al. L'Apostolato dei Laici - Decreto "Apostolicam Actuositatem”. Brescia: Queriniana, 1966.

PIRONIO, E. La vocazione dei laici alla santità. In: "Rivista di Vita Spirituale", 16/IV-V (1987), pp. 390-406.

REY, Dominique. Accoglienza dei movimenti e delle nuove comunità nelle Chiese particolari. In: Pontificium Consilium pro Laicis. Pastori e Movimenti Ecclesiali. Seminario di studio per i vescovi (Rocca di Papa, 15 - 17 maggio 2008). Città del Vaticano: LEV, 2008, pp. 103-119.

RAMBALDI, G. Uso e Significato di 'Carisma' nel Vaticano II. In: "Gregorianum" 56/1 (1975), pp. 141-162.

. Carismi e Laicato nella Chiesa. In: "Gregorianum" 68/1-2 (1987), pp. 57-101.

RATZINGER, J. I Movimenti ecclesiali e la loro collocazione teologica. In: Pontificium Consilium pro Laicis. I Movimenti nella Chiesa - Atti del Congresso Mondiale dei Movimenti Ecclesiali (Roma, 27-29 maggio 1998). Città del Vaticano: LEV, 1999, pp. 23-51. 
RYŁKO, S. Il Concilio Vaticano II, pietra miliare nel cammino del laicato cattolico. In: Pontificium Consilium pro Laicis. Atti del Congresso del Laicato Cattolico - Testimoni di Cristo nel nuovo Millennio (Roma, 25 30 Novembre 2000) Città del Vaticano: LEV, pp. 115-142.

SCABINI, P. Vocazione e missione dei laici nei documenti conciliari e postconciliare. In: "Rivista di Vita Spirituale", 16/IV-V (1987), p. 378-389.

STAFFORD, J. F. I Movimenti nell'Oggi della Chiesa. In: "Nuova Umanità" XXII (2000/1) n²127, Roma, 2000, pp. 35-49.

TAVEIRA, Alberto. Discerimento dei carismi: alcuni criteri pratici. In: Pontificium Consilium pro Laicis. Pastori e Movimenti Ecclesiali. Seminario di studio per i vescovi (Rocca di Papa, 15 - 17 maggio 2008). Città del Vaticano: LEV, 2009, pp. 97-102.

TRENTIN, G. Movimenti ecclesiali tra fede e storia. In: Imovimenti ecclesiali: esperienza e teologia. In: “Credere Oggi”, 5 (1983), n. 17, pp. 46-55.

VANHOYE, A. I Carismi nel Nuovo Testamento (ad uso degli studenti). Roma: Pontificio Istituto Biblico, 2002.

Renato da Silveira Borges Neto

Doutor em Teologia Dogmática pela Pontifícia Università di San Tommaso d'Aquino (Angelicum) - Roma. Professor no Instituto Superior de Teologia da Arquidiocese do Rio de Janeiro (ISTARJ). E-mail: renatosbn@yahoo.com.br Artigo Recebido em 28/11/2011 Artigo Aprovado em 30/03/2012 